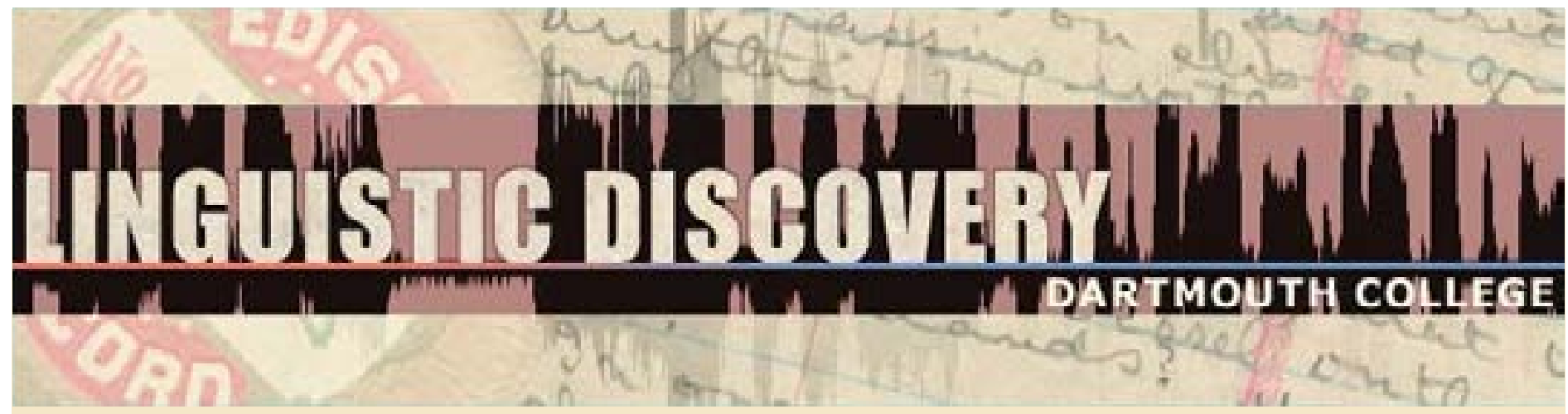

\begin{tabular}{|l|}
\hline Volume 9 \\
Issue 2 \\
2011 \\
\hline
\end{tabular}

\title{
Aspect in Chechen
}

Zarina Molochieva

University of California, Berkeley

doi: 10.1349/PS1.1537-0852.A.397

url: http://journals.dartmouth.edu/cgi-bin/WebObjects/ Journals.woa/1/xmlpage/1/article/397

\section{Linguistic Discovery}

Published by the Dartmouth College Library Copyright to this article is held by the authors. ISSN 1537-0852 linguistic-discovery.dartmouth.edu 


\title{
Aspect in Chechen
}

\author{
Zarina Molochieva
}

University of California, Berkeley

Max Planck Institute for Evolutionary Anthropology, Leipzig

\section{Introduction $^{1,2}$}

This paper deals with the aspectual system in Chechen (Nakh, Nakh-Daghestanian or Northeast Caucasian). Chechen has a very complex aspectual system. First, there are morphologically marked perfective and imperfective oppositions. There are also a habitual aspect and two kinds of progressive aspect: durative progressive and focalized progressive, which can in turn combine with other aspectual oppositions. The habitual can be combined with the focalized progressive and durative progressive. In addition, there is a full-fledged iterative aspect, which can be marked as perfective, imperfective, habitual, and progressive, as well. In order to better explain the semantics of each aspect type I analyze them separately. I argue that Chechen possesses an equipollent aspectual system. I also discuss the relationship between the imperfective and progressive aspect, and how they differ, and the semantic distinctions between iterative and habitual aspects in Chechen.

\section{Marking}

In Chechen, aspect is marked by stem alternation (vowel ablaut in the productive conjugations) (Beerle 1988, Handel 2003, Nichols \& Vagapov 2004). Depending on the underlying stem vowel, Chechen verbs can overtly distinguish up to seven stem forms. Some examples showing the different stem variations are illustrated in Table 1. Some verbs do not distinguish between perfective 1 and perfective 2 (for the witnessed tenses) stems (e.g. hwaaqa 'rub', ai' $a$ 'lift'), and some verbs are formed by partial suppletion (e.g. tuoxa 'hit', dahwa 'carry').

\begin{tabular}{|l|l|l|l|l|}
\hline Stem of the verb & $\begin{array}{l}\text { tuoxa } \\
\text { 'hit' }\end{array}$ & $\begin{array}{l}\text { dahwa } \\
\text { 'carry' }\end{array}$ & $\begin{array}{l}\text { hwaaqa } \\
\text { 'rub' }\end{array}$ & $\begin{array}{l}\text { ai'a } \\
\text { 'lift' }\end{array}$ \\
\hline Infinitive stem & tuoxa- & daa- & hwaaq- & ai'a- \\
\hline Imperfective stem & tuux- & dahwa- & hwooq- & oi'u- \\
\hline Perfective stem 1 & toex- & de'a- & hwaeq- & ai'i- \\
\hline $\begin{array}{l}\text { Perfective stem 2 (for the } \\
\text { witnessed tenses) }\end{array}$ & tyyx- & de'a- & hwaeq- & ai'i- \\
\hline Infinitive iterative stem & diett- & qiehwa- & hwieq- & ii'a- \\
\hline Imperfective iterative stem & doettu- & qoehw- & hwoe- & yy'u- \\
\hline Perfective iterative stem & diiti- & qiihw- & hwiiq- & ii'i- \\
\hline
\end{tabular}

The stems appear in the following tenses and verb forms:

\footnotetext{
${ }^{1}$ I am grateful to Johanna Nichols for helpful comments on this paper.

${ }^{2}$ The research was supported by ELDP, London and the Max Planck Institute for Evolutionary Anthropology, Leipzig.
} 
1. Imperfective stem: present and past imperfect, future, simultaneous converb;

2. Perfective 1 stem: perfect, remote past, anterior converb;

3. Perfective 2 stem for the witnessed tenses: recent and remote witnessed past;

The finite tenses and converbs distinguish aspect as shown above. There are also three iterative stems. The iterative stem can be marked by stem alternation as well:

1. Imperfective iterative stem: present and past imperfect, future, simultaneous converb;

2. Perfective iterative stem: perfect, remote past, anterior converb;

The regular verbs fall into more than thirty ablaut classes (Nichols \& Vagapov 2004: 685). Each simplex inflected form is composed of one of the stem forms and a suffix or suffixes. Table 2 shows the suffixes used with different verb stems. The infinitive stem is used in the infinitive, imperative, and masdar. As mentioned above, the perfective 1 stem is used in perfective nonwitnessed tenses (perfect, remote past, resultative, and perfective evidential tenses), and in the formation of the anterior converb, which is used in the periphrastic perfective tenses. The perfective 2 stem is used only for the witnessed tenses. The imperfective stem is used in imperfective, habitual, progressive tenses, and in the formation of the simultaneous converb, which is used in the periphrastic imperfective tenses.

\begin{tabular}{|c|c|c|c|c|}
\hline Stem & Suffix & Verbal form & $\begin{array}{l}\text { Schematic } \\
\text { representation }\end{array}$ & $\begin{array}{l}\text { eeca } \\
\text { 'take/buy' }\end{array}$ \\
\hline \multirow{4}{*}{$\begin{array}{l}\text { Imperfective } \\
\text { stem }\end{array}$} & $-u /-a$ & Present imperfect & {$\left[\left[\text { STEM }_{\text {IPFV }}\right]-u\right]^{3}$} & оеси \\
\hline & $-(u) r a$ & Past imperfect & {$\left[\left[\mathrm{STEM}_{\mathrm{IPFV}}\right]-r a\right]$} & oecura \\
\hline & $-(u) \operatorname{sh} d u$ & Simultaneous converb & {$\left[\left[\left[\right.\right.\right.$ STEM $\left.\left._{\text {IPFV }}\right]-s h\right]$ AUX $]$} & oecush du \\
\hline & $-r a d u$ & Future & {$\left[\left[\left[\right.\right.\right.$ STEM $\left.\left._{\text {IPFV }}\right]-r a\right]$ AUX $]$} & oecura du \\
\hline \multirow[t]{2}{*}{ Perfective stem 1} & $\begin{array}{l}-(a) n a \\
-(a) n a d u\end{array}$ & $\begin{array}{l}\text { Perfect, } \\
\text { anterior converb }\end{array}$ & $\begin{array}{l}{\left[\left[\mathrm{STEM}_{\mathrm{PFV}}\right]-n a\right]} \\
{\left[\left[\left[\mathrm{STEM}_{\mathrm{PFV}}\right]-n a\right] \mathrm{AUX}\right]}\end{array}$ & $\begin{array}{l}\text { iacna } \\
\text { iacna du }\end{array}$ \\
\hline & -niera & Remote past & {$\left[\left[\mathrm{STEM}_{\mathrm{PFV}}\right]-\right.$ niera $]$} & iacniera \\
\hline \multirow{2}{*}{$\begin{array}{l}\text { Perfective stem } 2 \\
\text { (for witnessed } \\
\text { tenses) }\end{array}$} & $-i$ & Recent witnessed past & {$\left[\left[\mathrm{STEM}_{\mathrm{PFV}}\right]-i\right]$} & iici \\
\hline & $-(i) r a$ & Remote witnessed past & {$\left[\left[\mathrm{STEM}_{\mathrm{PFV}}\right]-i r a\right]$} & iicira \\
\hline
\end{tabular}

Table 2: Suffixes with the different stems

\section{Definition of Aspect Types in Chechen}

In this section I show that aspect is marked by stem ablaut combined with tense suffixes and auxiliaries. I also show the semantic scope of each constituent of the Chechen tense-aspect system.

Perfective indicates a temporally bounded situation. The situation has reached its final point, and is viewed as a single whole, 'without distinction of the various separate phases that make up that situation' Comrie (1976:16). The morphology of the perfective aspect is represented in the

\footnotetext{
${ }^{3}$ The square brackets denote the semantic scope. STEM $\mathrm{IPFV}_{\text {/PFV }}$ denotes a perfective or imperfective stem. AUX denotes auxiliary.
} 
following scheme: [[STEM $\mathrm{PFv}]-n a /$-niera $]$.

Imperfective indicates an uncompleted situation. According to Comrie's definition (1976: 16), attention is paid to the 'internal structure of the situation'. The situation took place, and whether the situation reached its endpoint (i.e. whether the situation is completed) is not indicated: $\left[\left[\mathrm{STEM}_{\mathrm{IPFV}}\right]-s h /-r a /-u\right]$.

Habitual expresses a situation that usually repeats on different occasions over a period of time. The habitual aspect indicates that the situation usually occurred but whether the individual or total occurrence of the situation is completed is not in question. The periphrastic tenses are morphologically marked as habitual: $\left[\left[\left[\mathrm{STEM}_{\mathrm{IPFV}}\right]-s h\right] \mathrm{HAB}_{\mathrm{AUX}}\right]$. The synthetic tenses are not overtly marked as habitual, but may have a habitual meaning: [[STEM $\mathrm{IPFv}]-r a]$.

Durative progressive denotes a situation in process that can occur over a longer time span. It is mostly used when the action takes place at the moment of speech, or simultaneously with some other action. Durative progressive is available for the stative verbs, but not for the semelfactive and totally terminative verbs: [[[STEM $\mathrm{IPFv}]-s h] \mathrm{AUX}]$.

Focalized progressive emphasizes a short period of time where the action is in process. It is mostly used to express a situation which occurs simultaneously with some other action. In contrast to the durative progressive aspect, the focalized progressive is only available for accomplishment verbs. The progressive tenses do not imply the completeness of the action; they indicate that the action was in process, and whether the action is completed is not relevant: $\left[\left[\left[\mathrm{STEM}_{\mathrm{IPFV}}\right]-s h\right] \mathrm{AUX}_{\mathrm{PROG}}\right]$.

Durative progressive habitual expresses a durative progressive situation that is represented as habitual. The situation is in process in a longer time frame on different occasions. The scope of the habitual is over the durative progressive. The action as a whole is not completed:

[[[STEM $\left.\left.\left.\mathrm{IPFV}_{\mathrm{I}}\right]-s h\right] \mathrm{AUX}_{\mathrm{HAB}}\right]$.

Focalized progressive habitual implies a situation that usually occurs, and is in progress for a short period of time. The habitual scope is over the focalized durative progressive. The short period of time is focalized; the action as a whole is not completed:

$\left.\left[\left[\left[\mathrm{STEM}_{\mathrm{IPFV}}\right]-s h\right] \mathrm{AUX}_{\mathrm{PROG}}-s h\right] \mathrm{AUX}_{\mathrm{HAB}}\right]$.

Iterative indicates a situation that occurs on one occasion in some period of time. The iterative situation consists of a number of subevents which are viewed as a single event. The iterative can be marked as perfective, imperfective, habitual, and durative progressive but not with the focalized progressive: [[STEM ${ }_{\text {ITER:IPFV }]-s h /-r a]}$.

Iterative perfective is used to indicate the completeness of iterative situations. For instance, the range of the iterative subevents has reached its endpoint; the situation as a whole is completed: [[[STEM ${ }_{\text {ITER:PFV] }}$-na/-niera] .

Iterative imperfective indicates a number of iterative subevents viewed as a single situation not completed. The iterative situation took place but did not reach its endpoint; the situation is not 


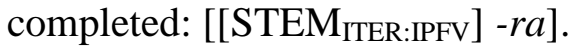

Iterative durative progressive implies a progressive situation that occurs repeatedly on one occasion. The iterative progressive situations consist of a number of subevents which are viewed as a single whole: [[[STEM $\left.{ }_{\text {ITER:PFV }}-s h\right]$ AUX $\left._{\mathrm{HAB}}\right]$.

Iterative durative progressive habitual implies a situation that occurs repeatedly in the habitual context. The number of subevents (viewed as a single event) occurs on different occasions (i.e. habitual context). The habitual scope is over the whole construction: [[[STEM $\mathrm{STER}: \mathrm{IPFV}]-s h]$ AUX $\left.\mathrm{X}_{\mathrm{HAB}}\right]$.

\section{Perfective vs Imperfective}

Comrie's (1976) discussion of grammatical aspect mainly focuses on the distinction between perfective and imperfective. According to Comrie (1976), the imperfective aspect focuses on the internal structure of the situation, whereas the perfective refers to the situation as a single whole implying the completion of the situation. Chechen overtly contrasts imperfective and perfective aspect in the verbal morphology. First I show the use and definition of the imperfective and perfective aspect. In section 3.1 I consider the question whether the aspectual opposition in Chechen is privative or equipollent. An event is marked as perfective when it has reached its endpoint. In discussions about the morphological marking of the imperfective or perfective aspect the question Have you read the book? is often used. The question asks whether the addressee has read the book and finished it. In Chechen, the answer to this question can only be in the perfective when the event is/has been completed $(1,2,3)$. The past imperfect and the past durative progressive cannot be used in such cases (see section 3.1). (4-5) indicate the uncompleted event which is still in progress (5).

Perfect

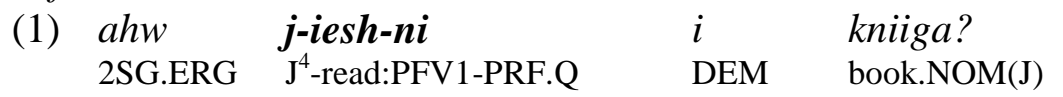

'Have you read this book? (Have you read and finished it?)'

Perfect

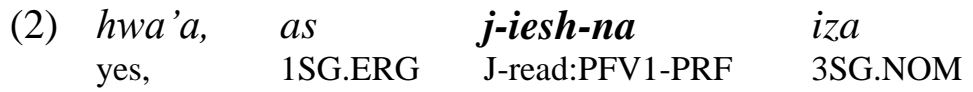

'Yes, I have read it.'

Remote witnessed past

$\begin{array}{llll}\text { (3) } h w a ' a, & \text { as } & \text { j-iishi-ra } & \text { iza } \\ \text { yes, } & \text { 1SG.ERG } & \text { J-read:PFV2-Rem.WPST } & \text { 3SG.NOM }\end{array}$

'Yes, I have read it.'

When the past imperfect is used, it indicates that the subject used to read the book, but did not finish it (4). (5) indicates that the subject was in the process of reading the book, and also did not

${ }^{4} \mathrm{~V}, \mathrm{~J}, \mathrm{D}$, and B denote gender classes 
finish it. These examples are grammatically correct, but they cannot be used as an answer to the question Have you read the book? if the subject has read the book and finished it, i.e. if the event is completed (cf. 2-3 and 4-5).

Past imperfect
(4) \#hwa'a, yes, $\begin{array}{ll}\text { as } & \text { j-oeshu-ra } \\ \text { 1SG.ERG } & \text { J-read:IPFV-IPRF }\end{array}$ iza 3SG.NOM
'Yes, I used to read it.'

\section{Durative progressive past

$\begin{array}{lllll}\text { \# hwa'a, } & \text { so } & \text { j-oeshu-sh } & \text { v-ara } & \text { iza } \\ \text { yes, } & \text { 1SG.NOM } & \text { J-read:IPFV-CVBsim } & \text { V-be.PST } & \text { 3SG.NOM } \\ \text { 'Yes, I was reading it.' } & & \end{array}$

The contrast between the perfective and imperfective can be clearly seen in (6a). (6a) indicates that the event doora 'built usually/sometimes' happened from time to time, but did not reach its endpoint, i.e. the house was not completed. The perfective dina indicates that the house is already finished, i.e. he was from time to time in the process of building the house (IPFV), but did not finish building (PFV).

\begin{tabular}{|c|c|c|c|c|}
\hline $\begin{array}{l}\text { сио } \\
\text { 3SG.ERG }\end{array}$ & $\begin{array}{l}c^{\prime} a a_{i} \\
\text { house.NOM(D) }\end{array}$ & $\begin{array}{l}\boldsymbol{d}-\boldsymbol{a}=\boldsymbol{m} \text { - } \boldsymbol{d}-\boldsymbol{o o}-\boldsymbol{r} \boldsymbol{a}, \\
\text { D-make:IPFV=EMPH-D-make:IPFV-IPRF }\end{array}$ & $\begin{array}{l}q i \\
\text { no more }\end{array}$ & $\begin{array}{l}i z a_{i} \\
\text { 3SG.NOM }\end{array}$ \\
\hline$d-i-n a=m$ & & ca-v-eeli-ra & & \\
\hline D-make:PFV & $1-\mathrm{CVBant}=\mathrm{EMPH}$ & NEG-V-finish:PFV2-Rem.WPST & & \\
\hline
\end{tabular}

'He was building a house, but he did not finish it.'

Instead of the past imperfect, the durative progressive can be used. (6b) indicates that the event was in progress, diesh vara 'was building a house', and did not reach its endpoint.

\begin{tabular}{|c|c|c|c|c|c|}
\hline $\begin{array}{l}i z a \\
\text { 3SG.NOM(V }\end{array}$ & $\begin{array}{l}c^{\prime} a a_{i} \\
\text { house.NOM(D) }\end{array}$ & $\begin{array}{l}d \text {-ie-sh } \\
\text { D-make }\end{array}$ & V-CVBsim & $\begin{array}{l}\text { v-ara, } \\
\text { V-be.PST }\end{array}$ & $\begin{array}{l}q i \\
\text { no more }\end{array}$ \\
\hline & $d-i-n a=m$ & \multicolumn{4}{|c|}{ ca-v-eeli-ra } \\
\hline 3SG.NOM & D-make:PFV1-CVBa & $=\mathrm{EMPH}$ & \multicolumn{3}{|c|}{ NEG-V-finish:PFV2-Rem.WPST } \\
\hline
\end{tabular}

'He was building a house, but he did not finish it.'

The difference between imperfective and perfective can be further illustrated by the verb dala 'die'. The imperfective form laara and perfective delira are used in (7). laara 'was dying' indicates that the event has not reached its endpoint, e.g., he was very close to dying, but he did not die, whereas delira 'has died' indicates that the event is completed. To express progressive situations (e.g. he is dying) with the verb dala 'die' the durative progressive is used (8).

$\begin{array}{llll}\text { (7) } \begin{array}{c}\text { \#xa }(n) \\ \text { 1PL/excl.GEN }\end{array} & \begin{array}{l}\text { luulaxuo } \\ \text { neighbour.NOM }\end{array} & \begin{array}{l}\text { hwoora } \\ \text { every }\end{array} & \begin{array}{l}\text { diinahw } \\ \text { day.LOC }\end{array}\end{array}$




$\begin{array}{lll}\text { laa-ra, } & q i & \boldsymbol{v} \text {-ala=m-ca- } \boldsymbol{v} \text {-eli-ra } \\ \text { die:IPFV-IPRF } & \text { no more } & \text { V-die:INF=EMPH-NEG-V-die:PFV2-Rem.WPST }\end{array}$

'Our neighbour was dying every day, but did not die., 5

$\begin{array}{llllll}\text { txa }(n) & \text { luulaxuo } & \text { lie-sh } & \text { v-ara } & \text { hwoora } & \text { diinahw, } \\ \text { 1PL/excl.GEN } & \text { neighbour.NOM } & \text { die:IPFV-CVBsim } & \text { V-be.PST } & \text { every } & \text { day.LOC }\end{array}$

qi $\quad$ v-ala $=m$-ca-v-eeli-ra

more V-die:INF=EMPH-NEG=V-die:PFV2-Rem.WPST

'Our neighbour was dying every day, but did not die.'

In combination with time adverbials denoting a short period of time (for instance, itt minootiahw 'in/for ten minutes', shina sahwtiahw 'in/for two hours', etc.), the past imperfect seems to allow the perfective reading. (9) can be interpreted as perfective as well as imperfective: the subject used to do his homework for two hours and did not finish it; but it may also mean that the subject used to do his homework in two hours and finished it each time. The past imperfect has mostly a habitual meaning, i.e. the habitual indicates a certain event which occurs repeatedly in a certain period of time. Each habitual subevent may be viewed as completed, but the situation as a whole is not completed. This can be represented by the following scheme: [[e] [e] [e] ${ }^{6} \ldots$ IPRF].

Past imperfect

\begin{tabular}{|c|c|c|c|}
\hline $\begin{array}{l}\text { shina } \\
\text { two }\end{array}$ & $\begin{array}{l}\text { sahwtiahw } \\
\text { hour.LOC }\end{array}$ & $\begin{array}{l}\text { urook-ash } \\
\text { lesson-PL.NOM(J) }\end{array}$ & $\begin{array}{l}\text { j-oo-ra } \\
\text { J-make:IPFV-IPRF }\end{array}$ \\
\hline
\end{tabular}

'He was working on his homework for two hours (and did not complete it).'

In constructions without time adverbials the past imperfect can only have an imperfective meaning. (10) indicates that the subject worked on his homework after coming from school, but he did not complete it.

Past imperfect

(10) urook-ash j-oo-ra cuo shkooliera c'a-v-e'a-cha lesson-PL.NOM(J) J-make:IPFV-IPRF 3SG.ERG school.ABL home-V-come:PFV1-CVBtemp 'He used to do (his) homework, when he came home from school.'

In (11) the result of the individual subevent may be perfective but the whole construction is viewed as imperfective. This can be visualized in the following schematic representation, in which the habitual has scope over the whole construction: [[[e] [e] [e]... -na (PFV)] -ra (IPFV)].

Past imperfect

shina

sahwtiahw

urookash

$j-i-n a$

v-oolu-ra

two hour.LOC lesson-PL.NOM(J) J-make:PFV1-CVBant

V-finish:IPFV-IPRF

'He would finish his homework in two hours.'

\footnotetext{
${ }^{5}$ Example (7) is used ironically, e.g. the neighbour was not really dying, but was claiming he was ill and about to die.

${ }^{6}[\mathrm{e}]$ denotes an event.
} 
In contrast to telic verbs, atelic verbs can be interpreted only as imperfective even when they are used in construction with time adverbials. This is because they express actions without any results, for instance, daxa 'go' or bolx ba 'work' (bolx ba 'work' is a light verb construction which literally means bolx 'work' $b a$ 'make'). The difference between perfective bolx bira 'have worked' and imperfective bolx boora 'used to work' is that bolx bira means that the event has reached its final endpoint (e.g. the work will not be continued). The imperfective bolx boora means the subject was working and maybe will continue at some later point (12-13).

\section{Past imperfect}

(12) shina

two

sahwtiahw

bolx

hour.LOC

work.NOM(B)

b-oo-ra

cuo

'He worked for two hours (and did not finish his work).'

Perfect

(13)

\section{shina}

two

sahwtiahw

hour.LOC

'He worked for two hours.' bolx
work.NOM(B) $\boldsymbol{b}$-i-ra
B-make:PFV2-PRF cuo

3SG.ERG

\subsection{Privative or equipollent?}

In the previous section we have seen the differences between perfective and imperfective, and I presented both as being morphologically marked. In some languages, notably Slavic languages, the opposition of perfective to imperfective is a privative one where the perfective has some positive grammatical meaning and the imperfective is just absence of that meaning (e.g. Russian, perfective implies a specific time juncture and imperfective does not) (Forsyth 1970, Comrie 1976, Dickey 2000), in Chechen, the opposition is equipollent, with each aspect having a discrete positive meaning. There are no known cases of aspect neutralization in Chechen and no contexts where one aspect assumes the meaning or function of the other. When the question is asked in the perfective (e.g. perfect or remote witnessed past), it implies the addressee has completed the action, e.g. the addressee has read and finished the book (14a). The question is also in the perfective if the action is completed, whereas the imperfective requires the incompleteness of the event (14a-d).

\section{Perfect \\ $\begin{array}{lllll}\text { (14a) } & \text { ahw } & \text { j-iesh-ni } & i & \text { kniiga } \\ & \text { 2SG.ERG } & \text { J-read:PFV1-PRF.Q } & \text { DEM } & \text { book }\end{array}$ \\ 'Have you read this book? (Have you read and finished it?)'}

\section{Perfect \\ (14b) ha'a, j-iesh-na \\ yes, J-read:PFV1-PRF \\ 'Yes, (I) have read (it, and finished it).'}


Past imperfect

$\begin{array}{llll}\text { (14c) } & \text { as } & \text { j-oeshu-ra } & \text { naggahw } \\ & \text { 1SG.ERG } & \text { J-read:IPFV-IPRF } & \text { sometimes } \\ & \text { 'I sometimes read it, (but did not finish it).' }\end{array}$

As already discussed, the perfective is used to indicate the completeness of the event. In questions the imperfective verb indicates that the speaker is not interested in whether the event was completed or not, but he is interested in the process of the event. The verb form used in the question is based on the speaker's assumption, for instance, the perfect is used when the speaker assumes that the situation is already completed, whereas the durative progressive implies the speaker's assumption that the situation might be still in progress. The past imperfect is used when the speaker assumes that the situation occurred repeatedly, and whether the situation reached its endpoint is not relevant. In (15a) the perfect is used and the speaker is interested in whether the addressee has finished writing the letter. The speaker knows/assumes that the event is completed, e.g. the addressee has written the letter and is not going to continue to write it. The verb form in the answer depends on the one used in the question: if in the question the perfective verb form is used, this will be mirrored in the answer. (15b) and (15c) answer the question (15a). (15b) indicates the letter is finished, whereas (15c) indicates that the addressee is in the process of writing the letter, but has not finished it.

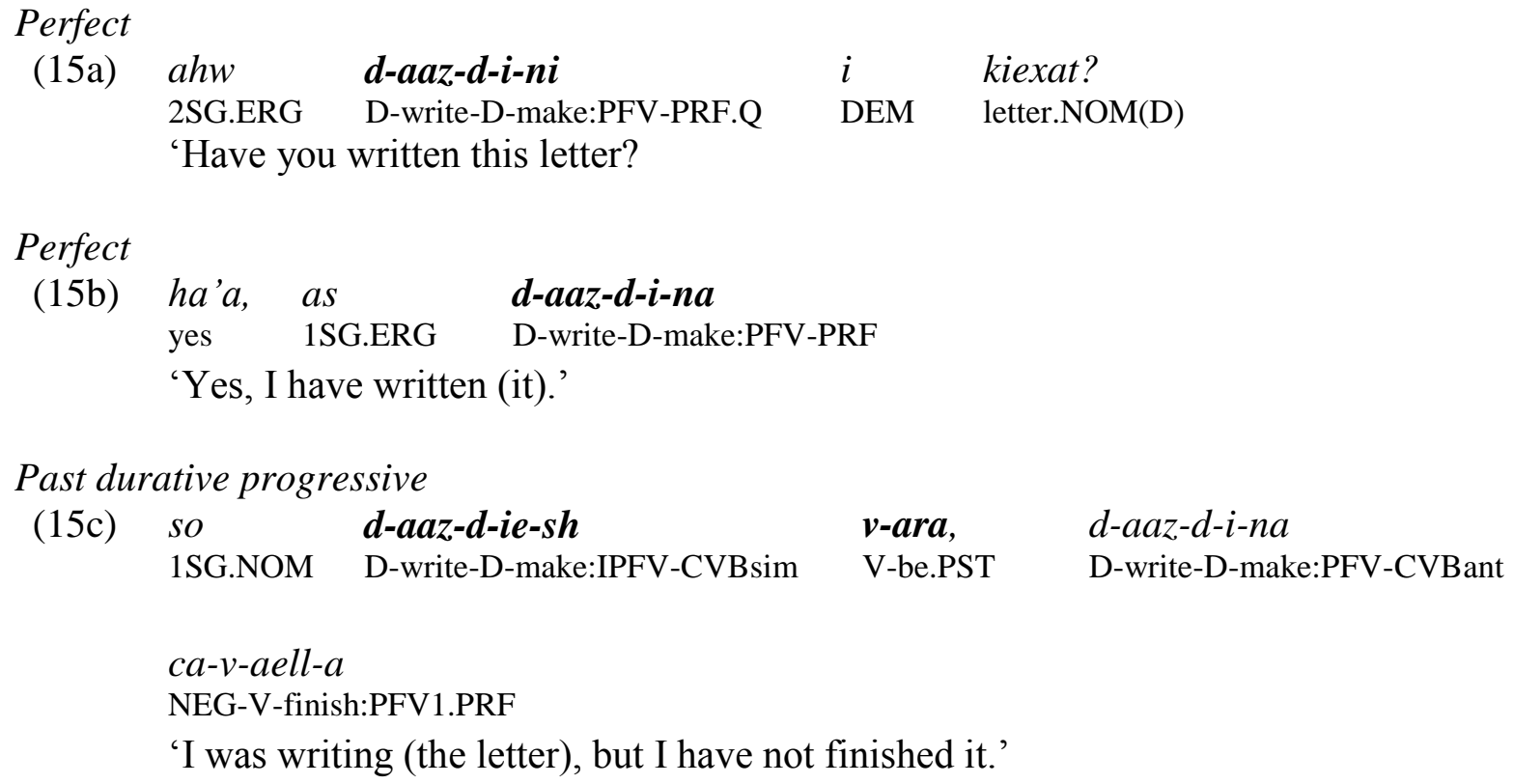

As discussed above, the aspect of the verb in the question is based on the speaker's assumption or knowledge. The question may be also asked in the progressive durative if the speaker assumes that the event is or was in progress and did not reach its endpoint (16a). In these cases the answer must also be in the durative progressive (16b), and using the perfective verb is infelicitous (16c). 
Past durative progressive
(16a) hwo j-ar-i kiexat d-aaz-d-ie-sh?
2SG.NOM J-be.PST-Q letter.NOM D-write-D-make:IPFV-CVBsim
'Were you writing the letter?'
(16b) ha'a, so j-ara (i d-aaz-d-ie-sh)
yes, 1SG.NOM J-be.PST DEM D-write-D-make:IPFV-CVBsim
'Yes, I was.'

\section{Perfect \\ (16c) \#ha'a, as d-aaz-d-i-na \\ yes, 1SG.ERG D-write-D-make:PFV-PRF}
'Yes, I have written (it).'

This can be further illustrated with the following context. Assume that a healer gave medicine to a patient's mother. The patient was to take it for a week. When the healer sees the mother two days later (the week is not over yet) he asks the following question in the durative progressive (17). The healer assumes that the patient is taking the medicine, and probably has not finished taking it, because the patient is expected to finish the medicine only after a week.

Present durative progressive

\begin{tabular}{|c|c|c|c|c|}
\hline (17) & $\begin{array}{l}\text { molxa } \\
\text { medicine.NOM }\end{array}$ & $\begin{array}{l}\text { molu-sh } \\
\text { drink:IPFV-CVBsim }\end{array}$ & $\begin{array}{l}\boldsymbol{v}-\boldsymbol{u}-\boldsymbol{i} \\
\text { V-be.PRS-Q }\end{array}$ & $\begin{array}{l}i z a ? \\
\text { 3SG.NOM }\end{array}$ \\
\hline
\end{tabular}

'Is she taking the medicine?'

When the healer sees the mother one week later he assumes that the patient has finished taking the medicine. In such cases the perfect is used (18).

Perfect

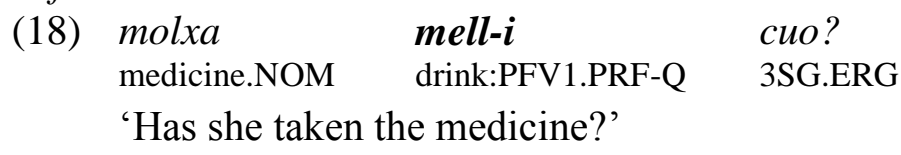

The past imperfect is used when the speaker assumes that the subject was taking the medicine repeatedly (19).

Past imperfect

(19) molxa

$\begin{array}{lll} & \text { molu-ri } & \text { cuo? } \\ \text { medicine.NOM } & \text { drink:IPFV-IPRF.Q } & \text { 3SG.ERG }\end{array}$

'Did he (usually) take the medicine?'

The use of the perfect (or other perfective tenses, e.g. witnessed, resultative tenses) requires the completion of the event, and the imperfective tenses imply an event which has not reached its endpoint. Whether the event is completed or is/was in progress is mostly based on the speaker's assumptions, experiences or presupposition. There is no default or neutral form; the speaker has 
to make a specific assumption. Therefore, an equipollent analysis of the aspectual system of Chechen seems to be most appropriate.

\section{The Progressive Aspect}

According to Dahl (1985:92), 'in languages with a perfective-imperfective distinction, the prototypical progressive contexts would be imperfective.' The imperfective and progressive are often treated as 'partially or wholly identified' (ibid.). Comrie (1976: 32ff.) considered the progressive as a type of the imperfective aspect. According to Comrie (ibid.: 33), in some languages (e.g. English), the use of the progressive forms is obligatory, i.e. the progressive and non-progressive cannot be substituted for one another. In others, the use of the progressive is optional (e.g. Spanish, Italian), i.e. the non-progressive can also have the progressive reading. Chechen belongs to the languages where the use of the progressive forms is obligatory. Chechen distinguishes two kinds of progressive aspect: durative progressive and focalized progressive. In this section I explain how Chechen's progressive aspect relates to the imperfective, and how progressive differs from imperfective. As mentioned in the previous section, the aspectual distinction expressed by stem form alternation is perfective and imperfective. The progressives are marked as imperfective (they have the same stem alternation as the present, past imperfect). The progressives (focalized and durative) are expressed periphrastically, i.e. by combining the simultaneous converb $-(u) s h$ and one of the auxiliaries $d u$ (durative progressive) and doall (focalized progressive). The progressives imply a situation which occurs simultaneously with some other situation. According to Dahl's TAM questionnaire (1985), the following example shows the "prototypical occurrence of the progressive "7. The progressive verbs in (20) indicate an ongoing situation which may occur simultaneously with some other situation (e.g. during the speaker's stay at his brother's place).

\section{Present durative progressive}

$$
\begin{aligned}
& \begin{array}{ll}
s a(n) & \text { vasha } \\
1 \text { SG.GEN } & \text { brother.NOM(V) }
\end{array} \\
& \text { kiexat / kiexat-ash } \\
& \text { letter.NOM(D) / letter-PL.NOM(D) } \\
& v-u \text { / v-oall } \\
& \text { V-be.PRS / V-be.PROG.PRS } \\
& \text { 'My brother is writing a letter /letters.' }
\end{aligned}
$$$$
d \text {-aaz-d-ie-sh }
$$$$
\text { D-write-D-make:IPFV-CVBsim }
$$

This can be further illustrated within the following examples. (21) indicates that the action was already in process when they came in. The action already started before they entered the room, and has happened only once, i.e. the progressive goitush vara does not have habitual meaning. (21) indicates that Salman was showing the pictures when we came in, and probably showed them several times during our stay in the room. The imperfective forms (the present and past imperfect) do not exclude the habitual interpretations, whereas the progressive cannot have the habitual reading.

Past durative progressive
(21)
chu-d-oevl-cha
1PL/excl.NOM inside-D-finish:PFV1:PL-CVBtemp
Salmaan
surt-ash
Salman.NOM(V)
pictures-PL.NOM

${ }^{7}$ Dahl's TAM (1985) Q 5: What your brother DO right now? = What activity is he engaged in? 


\section{goitu-sh v-ara}

show:IPFV-CVBsim V-be.PST

'When we came in, Salman was already showing the pictures (to the persons who were in the room).' [Salman started to show the pictures before we came in, and when we came in, he was in the process of showing the pictures.]

Past imperfect

(22)
txo
chu-d-oevl-cha
1PL/excl.NOM

Salmaana-s

Salman-ERG surt-ash

pictures.PL.NOM

\section{goitu-ra}

show:IPFV-IPRF

'When we came in, Salman was about to show the pictures.'

As already mentioned, the progressive aspect has two subcategories: durative and focalized progressive. The use of the focalized progressive in Chechen is obligatory when the speaker emphasizes the particular point in time when the event happened. The progressive indicates the 'focalization point' in time overlapping with the progressive event (Bertinetto 2000a, Johanson 2000). Bertinetto et al. (2000b) isolated three main types of progressive: focalized, durative, and absentive. 'focalized' progressive constructions are those expressing the notion of an event viewed as ongoing at a single point in time [...]', whereas 'durative' progressive constructions are those that are evaluated relative to a larger interval of time [...].' The Chechen focalized progressive also focuses on a single point in time, whereas the durative progressive is used to express larger time frames. In (23) the progressive event is focalized. The time boundary of the event is not determinate, i.e. the event may continue after they came in. The speaker points out the event within the time of arriving. The duration of the whole event is not determinate.

Focalized progressive

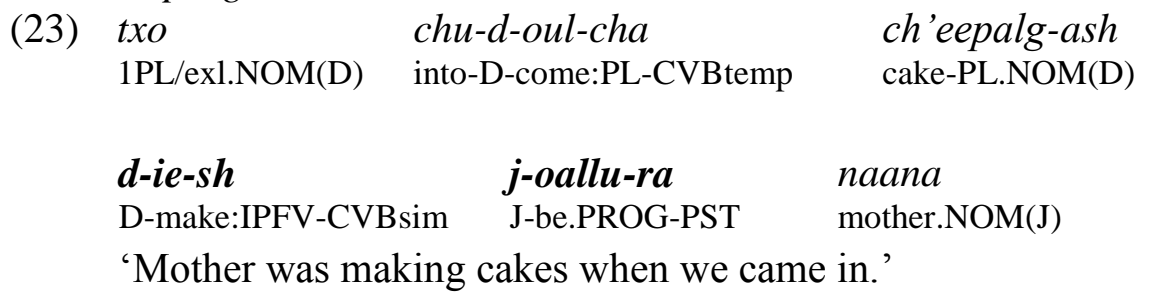

In example (24) the durative progressive is used. The situation is unbounded and the event happened in a larger time frame. The event was in progress the whole day, and similar to the focalized progressive, the duration of the event is not determinate. The focalized progressive in this construction is ungrammatical (25).

Durative progressive

\begin{tabular}{|c|c|c|c|c|c|}
\hline 24 & saaralca & bezhnash & $\begin{array}{l}\text { d-aazho-sh } \\
\text { D-oraze.IPFV_CVBsim }\end{array}$ & $\begin{array}{l}v \text {-ara } \\
\text { V-be PST }\end{array}$ & aan \\
\hline
\end{tabular}

'Salman was watching the cows all day long.' 
Focalized progressive

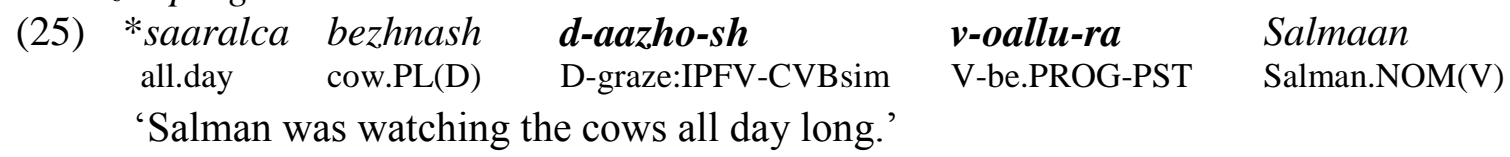

\subsection{Focalized progressive vs. durative progressive}

The focalized and durative progressive both indicate a situation in progress. However, they differ in some aspectual properties. Table 3 shows the differences between the focalized progressive and the durative progressive. The focalized progressive forms have very restricted usage with Aktionsart categories, and also with verbs requiring a larger time frame.

\begin{tabular}{|l|c|c|c|c|c|c|}
\hline & large time frame & habitual & iterative & stative & activity & $\begin{array}{l}\text { achievement / } \\
\text { semelfactive }\end{array}$ \\
\hline $\begin{array}{l}\text { Focalized } \\
\text { progressive }\end{array}$ & - & + & - & - & - & - \\
\hline $\begin{array}{l}\text { Durative } \\
\text { progressive }\end{array}$ & + & + & + & + & + & - \\
\hline
\end{tabular}

To start with the simplest case, semelfactives do not take the progressive aspect at all. Semelfactive 'cough' cannot be used with either progressive $(26,27)$. Only if the semelfactive verb is iterative (28) the progressive can be used.

Durative progressive

(26) *Salmaan Salman.NOM(V)

jouxar-sh tuuxu-sh v-u cough.NOM-PL hit.IPFV-CVBsim V-be.PRS

Intended meaning: 'Salman is coughing.'

Focalized progressive

(27) *Salmaan jouxar-sh tuuxu-sh v-oall Salman.NOM(V) cough.NOM-PL hit:IPFV-CVBsim V-be.PROG.PRS Intended meaning: 'Salman is coughing.'

\section{Durative progressive iterative}
(28) Salmaan
jouxar-sh
j-oettu-sh
$v-u$
Salman.NOM(V)
cough.NOM-PL J-hit:ITER:IPFV-CVBsim
V-be.PROG.PRS
Intended meaning: 'Salman is coughing.'

The 'large time frame' type is represented by verbs such as build a house. The event is represented as uncompleted during a stretch of time of definite duration. The initial and final boundaries of the event are not determined. (28)-(29) show that this verb is compatible only with the durative progressive and not with the focalized progressive. Another verb with a large time frame is diesha 'study' $(30,31)$. 
Durative progressive
(28) daada
c'aa
d-ie-sh
$\boldsymbol{v}-\boldsymbol{u}$
father.NOM(V)
home.NOM(D)
D-make:IPFV-CVBsim
V-be.PROG.PRS

'(My) father is building a house.'

Focalized progressive

*daada

c'aa

d-ie-sh

v-oall

father.NOM(V) home.NOM(D)

D-make:IPFV-CVBsim V-be.PROG.PRS

Intended reading: '(My) father is building a house.'

Durative progressive

luulaxuo-in
neighbour-GEN

$k^{\prime}$ ant

d-oeshu-sh

$v-u$

boy.NOM(V)

D-study:IPFV-CVBsim

V-be.PRS

'The son of (our) neighbours is studying (at the university).'

Focalized progressive

$\begin{array}{llll}\text { *luulaxuo-in } \quad \text { k'ant } & \text { d-oeshu-sh } & \text { v-oall } \\ \text { neighbour-GEN } & \text { boy.NOM(V) } & \text { D-study:IPFV-CVBsim } & \text { V-be.PROG.PRS } \\ \text { Intended reading: 'The son of (our) neighbours is studying (at the } \\ \text { university).' }\end{array}$

These two examples show that the use of progressives is constrained by the Aktionsart type of the verb.

\section{Habitual Aspect}

The habitual aspect expresses a situation that usually repeats on different occasions over some period of time. It is overtly marked only in the periphrastic tenses by one of the auxiliaries xylu or xilura (e.g. durative progressive habitual, focalized progressive habitual, resultative tenses). The synthetic tenses (e.g. present, past imperfect) are not morphologically marked as habitual, but may have habitual meaning depending on the context and the presence of time adverbials such as kest-kesta 'often', hoora diinahw/wyyranna 'every day/evening', etc cf. 32-33). Only imperfective tenses (e.g. present and past imperfect) may have habitual interpretations.

Present imperfect (with habitual reading):

$\begin{array}{lccc}\begin{array}{l}\text { kest-kesta } \\ \text { often }\end{array} & \begin{array}{l}\text { saga-d-oogh-u } \\ \text { heart-D-come:IPFV-IPRF }\end{array} & \begin{array}{l}\text { kegi } \\ \text { 1SG.DAT } \\ \text { small }\end{array} \\ \begin{array}{l}\text { d-ol-u-sh } \\ \text { D-be-PTCP-CVBsim time.LOC }\end{array} & \text { 1PL/excl.ERG behave-NZ } \\ \text { 'I often remember what we did in (our) childhood.' }\end{array}$

Present imperfect (without habitual reading):

$\begin{array}{lll}\text { haa, hinca } & \text { daga-d-oogh-u } & \text { suuna (...) } \\ \text { INTJ now } & \text { heart-D-come:IPFV-IPRF } & \text { 1SG.DAT }\end{array}$

'Ah, I remember now ...' 
The habitual aspect can combine with both types of progressive aspect: durative and focalized. The habitual progressive represents the progressive event in habitual context. For instance, the event toegush xylu 'used to be sewing' is in progress at a certain point of time repeatedly (34). Such situations can be viewed as both progressive and habitual. This can be visualized in the following schematic representation: $\left[\left[\mathrm{e}_{\mathrm{prog}}\right] \mathrm{HAB}\right]$, where the scope of the habitual meaning is over the whole construction.

\section{Present habitual durative progressive}
j-oqqa stag gaalie-sh
toegu-sh
xylu j-old person.NOM(J) sack-PL.NOM sew:IPFV-CVBsim be.HAB.PRS
'The old woman is always sewing sacks (e.g. when I come in).'

The habitual auxiliaries can combine not only with the progressives, but also with the resultative (which is marked as perfective). Resultative events are depicted in the habitual context, i.e. the perfective can combine with the habitual. However, the whole construction can be viewed as habitual (i.e. imperfective), but not perfective. The result is marked perfective (tiegna 'sewn, has sewn' in (35)), whereas the construction as a whole is presented in the habitual aspect (e.g. imperfective) (35). This is shown in the following schematic representation: $\left[\left[\mathrm{e}_{\mathrm{pfv}}\right] \mathrm{HAB}\right]$, where the scope of habitual is over the perfective.

\section{Present resultative habitual

\begin{tabular}{|c|c|c|c|c|}
\hline $\begin{array}{l}\text { j-oqqa } \\
\text { J-old }\end{array}$ & $\begin{array}{l}\text { stag-as } \\
\text { person-ERG }\end{array}$ & $\begin{array}{l}\text { gaalie-sh } \\
\text { sack-PL.NOM }\end{array}$ & $\begin{array}{l}\text { tieg-na } \\
\text { sew:PFV1-CVBant }\end{array}$ & $\begin{array}{l}\boldsymbol{x y l u} \\
\text { be.HAB.PRS }\end{array}$ \\
\hline
\end{tabular}

The habitual tenses and iterative both express the repetition of the event, the question arising here is how the habitual differs from the iterative (for details see Comrie 1976: 27ff, Brinton 1991: 53ff, Bybee et. al. 1994). The habitual expresses a situation which occurs frequently during an extended period of time, whereas the iterative refers to a number of repeated situations which 'can be viewed as a single situation, albeit with internal structure, and referred to by a perfective form' (1976: 27). This can be further illustrated with (36-37). (36) indicates that the imperfective event occurred repeatedly during an extended period of time (e.g. shiila jolchu xeenahw 'when it was cold'). The situation usually occurs at the time when it was cold, and the situation in question is not iterative. (37) indicates that the situation myylura 'drank tea several times' occurred several times on the same occasion wyyranna 'in the morning'.

Past imperfect

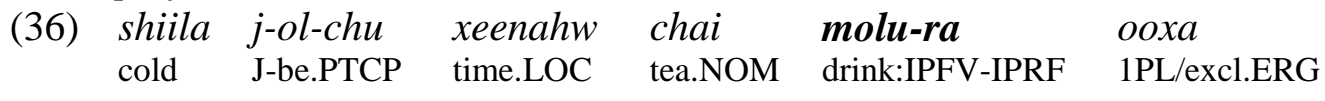

'We used to drink tea when it was cold.'

Past imperfect iterative

(37) wyyranna chai

morning.ADV tea.NOM drink:IPFV:ITER-IPRF 1PL/excl.ERG

'In the morning we drank tea a lot of times.' 
Moreover, the iterative aspect can combine with the habitual (e.g. iterative imperfective). For instance, (38) indicates that the iterative situation myylura 'drank a lot of times' occurred on different occasions. The iterative situation occurred within the habitual context: [[ITER] HAB].

Past imperfect iterative

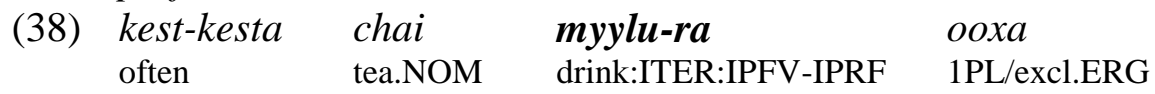

'We often drank tea (again and again).'

To sum up, the habitual indicates different events which occurred repeatedly, whereas the iterative aspect indicates repetition of the same situation. Moreover, the habitual cannot be perfective, whereas the iterative can be perfective (39).

\section{Perfect iterative}

$\begin{array}{lllll}\text { (39) ocu wyyranna duqqa chai miili-ra } & \text { ooxa } \\ \text { DEM morning.ADV many tea.NOM drink:ITER:IPFV-Rem.WPST } & \text { 1PL/excl.ERG } \\ \text { 'We drank tea (again and again) } & \text { that morning, } & \end{array}$

\section{The Iterative Aspect}

The iterative indicates a series of multiple events, which are interconnected and follow each other in a certain order. The iterative events are viewed as a single whole, e.g. the iterative form of the verb daxa 'go' implies multiple departures which took place in some particular period of time. The iterative does not imply any particular number of subevents or the length of the time frame during which the subevents take place. As mentioned in the previous section, there are iterative perfective and imperfective forms. The perfective iterative implies completion not of each subevent but of the whole series. For instance, in (40) 'push' is iterative and the sentence means that the subevents of pushing happened repeatedly and the whole situation of multiple pushings is completed.

\section{Perfect iterative \\ (40) mashian car.NOM(J)
j-uoxa='a-j-oex-na
J-break:INF=and-J-break:PFV1-CVBant
kest-kesta
often-REDPL \\ iza \\ 3SG.NOM

$\begin{array}{llll}\text { titti-na } & \text { Muusaa-s } & \text { hwal-latuo } & \text { ghierta-sh } \\ \text { push:ITER:PFV1-PRF } & \text { Musa-ERG } & \text { up-turn.on:INF } & \text { try:IPFV-CVBsim }\end{array}$ \\ 'The car broke down and Musa pushed it from time to time trying to turn it on.'}

The adverb kest-kesta 'often' shows that the situation happened repeatedly, i.e. Musa tried to turn on the car and pushed it repeatedly. The English verb push is an activity verb (cf. Vendler 1967, Dowty 1979). In contrast to English push, the Chechen verb tatta 'give a push' falls into an achievement Aktionsart category, i.e. the verb can imply a situation which happened repeatedly, whereas the activity implies that Musa and the car move steadily (40), and could be viewed as one event. Moreover, the adverb kest-kesta 'often' indicates that the situation 
happened repeatedly, i.e. Musa pushed the car and stopped and then pushed it again, etc. Example (40) can be represented as follows: [[[e] [e] [e]...]-na/-ra] PRF].

The iterative imperfective implies that the iterative situation was occurring in some time frame, but whether the situation reached its endpoint is not relevant. The iterative subevent was in process again and again. The situation as a whole was not completed at the moment of observing (41), and whether the situation will be completed is not in question. The schematic representation is the following: $[[[\mathrm{e}][\mathrm{e}][\mathrm{e}] \ldots-u s h /-r a]$ IPRF].

Durative progressive iterative

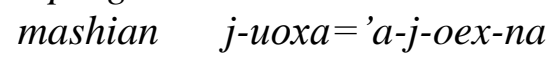

kest-kesta often-REDPL

iza

3SG.NOM

\title{
tyttu-sh \\ v-ara \\ Muusa \\ push:ITER:PFV-CVBsim \\ V-be.PST \\ Musa.NOM
}

'The car broke down and Musa pushed from time to time.'

Context: Musa was on the way home when his car broke down. He kept pushing the car again and again until he arrived home after a series of pushes.

However, the imperfective iterative can combine with the converb 'until' to indicate the completion of the situation even though the verb indicates only a process. In (42), the 'until' converb c'aqaachalca implies a kind of completion of the situation, and the situation tyttush vara 'was giving a push' has a kind of endpoint.

\section{Durative progressive iterative}

\author{
mashian \\ car.NOM(J)
}

$$
\begin{aligned}
& \text { j-uoxa }=\text { 'a-j-oex-na } \\
& \text { J-break:INF=and-J-break:PFV-CVBant }
\end{aligned}
$$

$$
\begin{aligned}
& \text { kest-kesta } \\
& \text { often-REDPL }
\end{aligned}
$$

$i z a$

3SG.NOM

$\begin{array}{llll}\boldsymbol{t y} \boldsymbol{t t u} \text {-sh } & \boldsymbol{v} \text {-ara } & \text { Muusa } & \text { c'a-qaacha-lca } \\ \text { push:ITER:IPFV-CVBsim } & \text { V-be.PST } & \text { Musa.NOM } & \text { home-arrive:INF-CVBuntil }\end{array}$

'The car broke down and Musa gave a push to it from time to time until he arrived home.' Context: Musa was on the way home when his car broke down. He kept pushing the car again and again until he arrived home after a series of pushes.

Example (40) shows that the iterative implies that the situation as a whole is completed (perfective) or not completed (imperfective), but does not imply anything about the completeness or incompleteness of each subevent (41-42).

\subsection{The iterative habitual}

As mentioned at the beginning of this paper, the iterative can also be habitual. The habituality of the situation is marked by the habitual 'be' auxiliary xylu for present time reference and xylura for past time reference. The iterative situation has habitual meaning [[[e] [e] [e]... IPFV] HAB]. Each iterative subevent $[\ldots[\mathrm{e}] . .$.$] is not viewed as habitual, but the situation as a whole has$ habitual meaning (43). 
Durative progressive habitual iterative
(43)
kest-kesta $i$ mashian often-REDPL DEM car.NOM(J)
nouq'ahw
$j-u o x a=' a-j-u u x-i$
road.LOC
J-break:INF=and-J-break:IPFV-CVBim.ant
$\begin{array}{ll}\text { iza } & \text { c'a-qaacha-alc } \\ \text { 3SG.NOM } & \text { home-arrive-CVBuntil }\end{array}$
tyttu-sh
xylu
Muusa
push:ITER:IPFV-CVBsim be.HAB.PRS
Musa.NOM
'The car often breaks down and Musa pushes it until he arrives home.'
Context: Musa goes to work by car every day. The car sometimes breaks down and Musa pushes it until he arrives home.

The perfective iterative appears in the perfect, pluperfect, and witnessed tenses but cannot combine with the resultative tenses and the recent witnessed past. The iterative tenses use the same verbal suffixes as the non-iterative tenses do. The resultative tenses indicate the result of a situation, while an iterative verb does not indicate that the situation has a result but simply points out how the situation proceeded. For instance, iterative miila 'drink' implies that a process of drinking something occurred repeatedly, but whether each iterative subevent has a result (e.g. drinking up the whole cup of tea) is not in question. Therefore, resultative and iterative are incompatible. As to the recent witnessed past, as discussed above, the perfective iterative indicates that all of the multiple subevents have reached their endpoint, while the recent witnessed past indicates an event which has just happened but was not witnessed by the speaker. The combination of iterative with the recent witnessed past would mean that each of the iterative subevents was witnessed just after it was finished, an implausible situation.

The imperfective iterative is not available for all focalized progressive tenses, but is available for the durative tenses. The focalized progressive emphasizes a particular point in time at which the event is happening, but an iterative event occurs repeatedly, and it is not possible to emphasize one of the iterative subevents or the whole series of them. Therefore the two categories are semantically incompatible.

\section{Concluding Remarks}

In Chechen, the perfective can have only perfective meaning, and the imperfective has only imperfective meaning, and there is no neutralization or default category. This is a major difference from Slavic languages, where the imperfective aspect is the default or neutral one and appears in contexts of neutralization. This systematic difference indicates that the distinction between equipollent and privative aspectual systems is a promising parameter for further typological research.

\section{Abbreviations}

ADV adverbial, AUX auxiliary, CVB converb, CVBsim simultaneous converb, CVBant anterior converb, DAT dative, DEM demonstrative, EMPH emphatic, ERG ergative, exl. exclusive, HAB habitual, INF infinitive, INTJ interjection, IPFV imperfective, ITER iterative, V, J, D, B gender class, LOC locative, NEG negation, NOM nominative, NZ nominalization, PFV perfective, PL plural, PRF perfect, PROG progressive, PRS present, PST past, PTCP participle, REDPL reduplication, Rem.WPST remote witnessed past, SG singular 


\section{References}

Beerle, Werner. 1988. A Contribution in the Morphology of the Simple Verb in Chechen. Studia Caucasiologica I (Proceedings of the Third Caucasian Colloquium, Oslo, July 1986), ed. by Thordarson, Fredrik, 9-37. Oslo: Institute for Comparative Research in Human Culture, Norwegian University Press.

Bertinetto, Pier Marco, Ebert, Karen, de Groot, Casper. 2000a. The Progressive in Europe. Tense and Aspect in the Languages of Europe, ed. by Dahl, Östen, 517-558. Berlin: Mouton de Gruyter.

-----. 2000b. The progressive in Romance, as compared with English. Tense and Aspect in the Languages of Europe, ed. by Dahl, Östen, 559-604. Berlin: Mouton de Gruyter.

Comrie, Bernard. 1976. Aspect. Cambridge: Cambridge University Press.

Dahl, Östen. 1985. Tense and Aspect Systems. Oxford: Blackwell.

Dickey, Stephen M. 2000. Parameters of Slavic Aspect: A Cognitive Approach. Stanford, CA: CSLI.

Dowty, David. 1979. Word Meaning and Montague Grammar. Dodrecht: Reidel.

Forsyth, James. 1970. A Grammar of Aspect: Usage and Meaning in the Russian Verb. Cambridge University Press.

Handel, Zev. 2003. Ingush inflectional verb morphology. Current trends in Caucasian, East European, and Inner Asian Linguistics: Papers in honour of Howard I. Aronson, ed. by Dee Ann Holisky and Kevin Tuite, 123-175. Philadelphia: Benjamins.

Johanson, Lars. 2000. Viewpoint operators in European languages. Tense and Aspect in the Languages of Europe, ed. by Östen Dahl, 265-308. Berlin: Mouton de Gruyter.

Nichols, Johanna and Vagapov, Arbi. 2004. Chechen-English and English-Chechen Dictionary. London/New York: Routledge.

Vendler, Zeno. [1957] 1967. Linguistics and Philosophy. Ithaca, New York: Cornell University Press.

Author's Contact Information:

University of California, Berkeley, CA \&

Max Planck Institute for Evolutionary Anthropology, Leipzig

molochie@eva.mpg.de 